Journal of Case Reports 2020;10(1):55-59

\title{
Multifocal GIST and Neurofibromatosis Type 1: Are They Related or Different Entity?
}

\author{
Aravinth Subramaniam¹, Nalankilli Palanisamy², Palanivelu Chinnusamy ${ }^{3}$, Divya Gnanasekaran ${ }^{1}$ \\ Departments of ${ }^{1}$ Pathology, ${ }^{2}$ Surgical Gastroenterology, ${ }^{3}$ Minimal Invasive and G.I Surgery, GEM Hospital and Research Centre, \\ Coimbatore-641045, Tamil Nadu, India.
}

\section{Corresponding Author:}

Dr. Aravinth Subramaniam

Email: aravinths1984@yahoo.com

This is an Open Access article distributed under the terms of the Creative Commons Attribution License (creativecommons.org/ licenses/by/3.0).

Received Accepted

Published

December 11, 2019

March 11, 2020

March 20, 2020

\begin{abstract}
Background: Neurofibromatosis type 1 (NF-1) also called as Von Recklinghausen's disease caused by functional loss of neurofibromin, a GTPase activating protein is a neurocutaneous disorder. It has multiple pigmentary and dermal lesions. Gastrointestinal stromal tumor (GIST) is one of the noted neoplasms to occur in neurofibromatosis type 1. Unlike sporadic GIST, NF-1 associated GIST is multiple and tends to occur in small intestine with different molecular pathway. Case Report: Here we are presenting a rare case of multifocal GIST in a 31 year old female with history of NF-1 managed in a tertiary care gastroenterology medical centre in India. Conclusion: This case of multifocal GIST associated with neurofibromatosis type 1 will be an eye opener for all doctors so that they investigate all neurofibromatosis patients to look for associated manifestations which are not evident clinically.
\end{abstract}

Keywords: Adult, Gastrointestinal Stromal Tumors, India, Neurofibromatosis, Small Intestine.

\section{Introduction}

Neurofibromatosis is a genetic disorder with autosomal dominant pattern of inheritance. It is classified into two subtypes, neurofibromatosis type 1 (NF-1) and neurofibromatosis type 2 (NF2). The incidence and prevalence of NF 1 are 1 in 2,500 to 3000 and 1 in 4000 to 5000 respectively [1]. NF-1 patients develop both benign and malignant tumors which includes neurofibroma, glioma, malignant peripheral nerve sheath tumors (MPNST), neuroblastoma, gastrointestinal stromal tumor (GIST), pheochromocytoma and breast cancer [2]. GIST associated with NF-1 are different when compared to sporadic GIST. NF-1 associated GIST is multiple and is commonly seen in small intestine. They rarely show KIT and PDGFRA mutation [2,3]. Incidence of GIST in NF-1 patient is 6 to 15 per one million and is the commonest mesenchymal tumor of the gastrointestinal tract
[4]. NF-1 associated GIST have different molecular pathway when compared to sporadic GIST [5]. We would like to present a rare case of multifocal GIST in a young 31 year female with history of NF-1.

\section{Case Report}

A 31 year old female came to our outpatient department with complaints of lower abdominal pain for four months. The associated complaints of malena, apthous ulcers, weight loss and decreased appetite were present. There was no history of abdominal distension, vomiting or constipation. Her vitals were stable. Multiple cutaneous nodules were seen throughout her face and body. Her blood investigations which included complete blood count, liver function test and renal function test were within normal range. Ultrasound abdomen showed multiple small nodular lesions from D4 to about $70 \mathrm{~cm}$ of jejunum. Computerized Tomography showed well defined heterogeneously 
enhancing mass measuring $11 \times 7.8 \mathrm{~cm}$ arising from proximal jejunum and cavitating into the lumen. There are other multiple well defined enhancing nodules in the proximal jejunal wall from duodenojejunal flexure largest one measuring $1.2 \times 1.2 \mathrm{~cm}$ [Fig.1]. The differential diagnosis included neurofibroma, GIST and schwannoma. Diagnostic laparoscopy was attempted, however due to large size of the tumor, procedure was converted to laparotomy. Jejunal mesentery was divided close to the bowel lumen in the entire length of involved segment. Jejunum was divided about $80 \mathrm{~cm}$ from duodenojejunal flexure and involved bowel was taken out to right side. Division of duodenum was done at D3 and D4 junction. Specimen was extracted; duodeno-jejunal anastomosis and enterotomy closure was done. Drain was placed near the anastomotic site.

Gross specimen showed small bowel with multiple serosal nodules ranging from $0.5 \mathrm{~cm}$ to 13 $\mathrm{cm}$ in diameter [Fig.2]. The mass was extending till the mucosal surface [Fig.3]. Microscopic examination showed spindle cell neoplasm with morphology favoring GIST [Fig.4]. Maximum mitotic count was 2 per 50 high power fields. Immunohistochemistry showed the neoplastic cells staining positive for CD-117 (c-kit), DOG-1 and negative for smooth muscle actin (SMA), desmin and S-100 [Fig.5-7]. Patient was treated with adjuvant imatinib for one year at a dosage of 400 mg daily.

\section{Discussion}

NF-1, autosomal dominant disease most commonly present as neurocutaneous disorder with 99\% cases having café au lait spots and cutaneous neurofibroma [1,6]. Neurofibromatosis type 1 develops due to mutation in NF-1 gene located on chromosome 17q11.2 which is responsible for making neurofibromin protein. Neurofibromin is a tumor suppressor protein which regulates rasguanosinetriphosphatase activity (GTPaseactivating protein- GAP) and keeps cells from

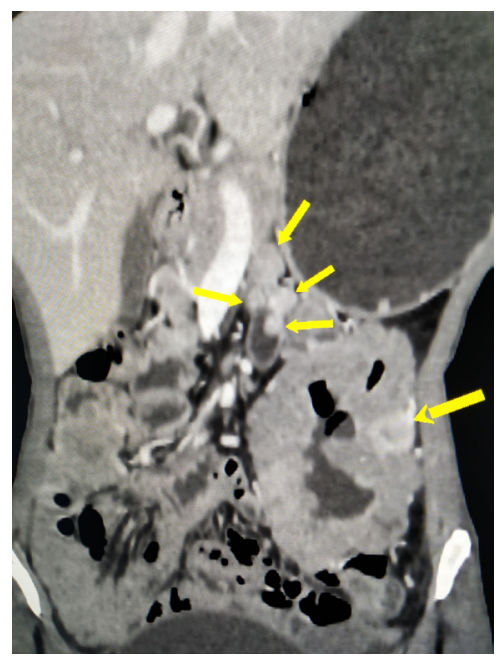

Fig.1: Computerized Tomography.

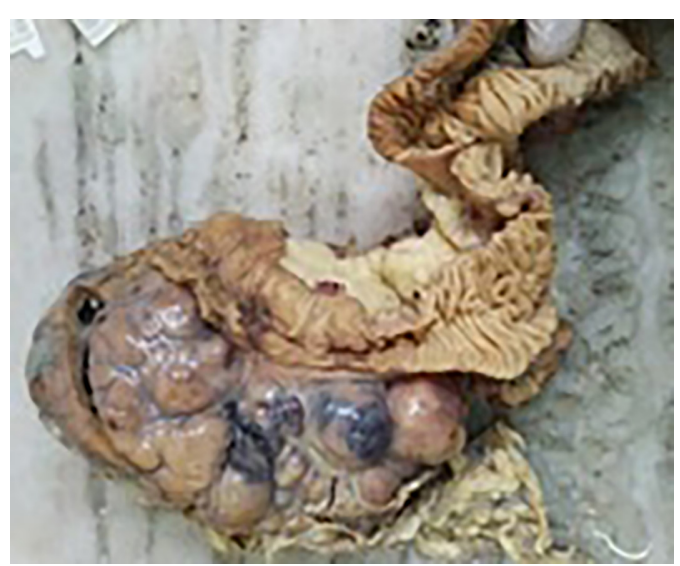

Fig.2: Gross picture showing small bowel wall with multiple serosal nodule.

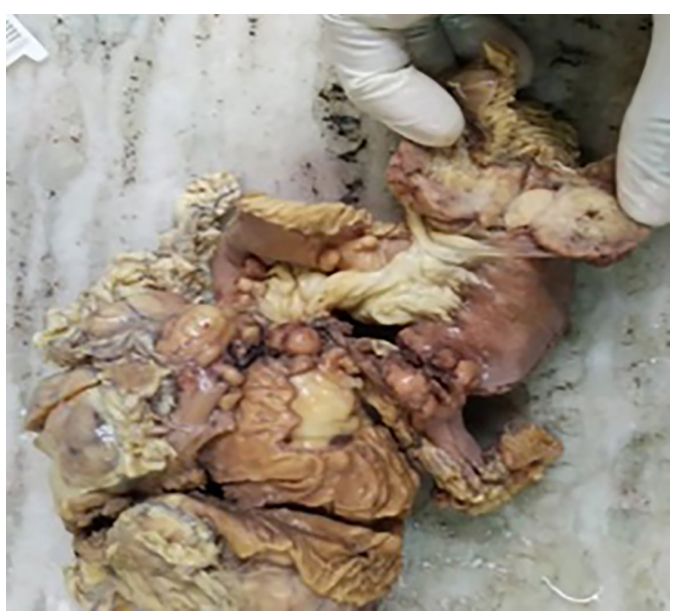

Fig.3: Gross picture showing nodule extending till the mucosal surface. 
growing in an uncontrolled way [7]. The clinical manifestation of neurofibromatosis type-1 can be classified into cutaneous and extra-cutaneous finding [8].

Incidence of gastrointestinal tumors in NF-1 patients ranges from $10-25 \%$ [9]. They present as neurogenic tumors, stromal tumors and endocrine tumors of periampullary region [9]. The GIST are commonly associated with NF-1 with $7 \%$ incidence [10] and are predominantly located in stomach and jejunum. They present with obstruction, bleeding, intussusception, volvulus or perforation. GIST is a mesenchymal tumor arising from CD-117 positive interstitial cells of cajal (ICC) [11], CD34 positive subset of ICC or primitive stem cells that differentiate into ICC [12] or smooth muscle cells [13]. 85\% of GISTs harbor activating KIT mutation [14-19].

In normal cell cycle nucleotide exchange (GDP by GTP) activates RAS protein and GTP hydrolysis converts GTP bound active RAS to GDP bound inactive form. GTPase activity intrinsic to normal RAS protein is accelerated by GTPase activating protein (GAP). Hence GAP functions as a barrier that prevents uncontrolled RAS activity. Neurofibromin-1 is one such RAS regulating GTPase activating protein (GAP) [21]. Mutation in C-KIT causes activation of RAS-MAP kinase pathway [22] and PI3kinase- AKT pathway [23]. Hence NF-1 associated GIST and sporadic GIST have overlap in their molecular pathway. More studies are needed to clarify the overlap between NF-1 associated and sporadic GIST.

Management of GIST depends on its resectability. Surgery becomes the first line of management for resectable tumors. For unresectable and metastatic GIST imatinib mesylate, a tyrosine kinase inhibitor is effective for both C-KIT and PDGFRA mutations. For wild type GIST such as NF-1 adjuvant therapy with imatinib should be considered on case basis as benefits are variable. Approved dose is $400 \mathrm{mg}$ /day. For exon 9 mutation

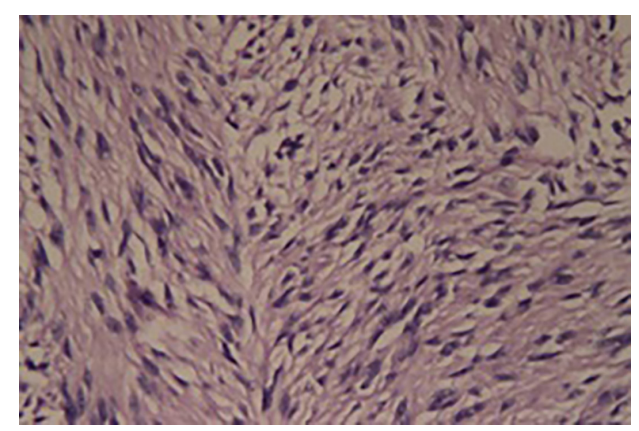

Fig.4: Hematoxylin and eosin stain showing spindle shaped neoplastic cells (High power view 40X).

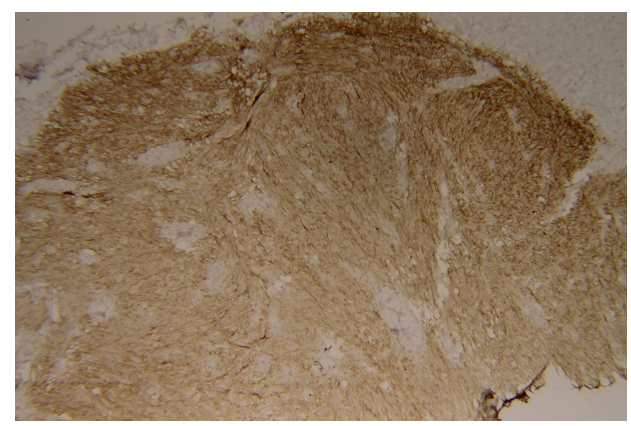

Fig.5: Immunohistochemistry showing neoplastic cells positive for CD117(c-kit).

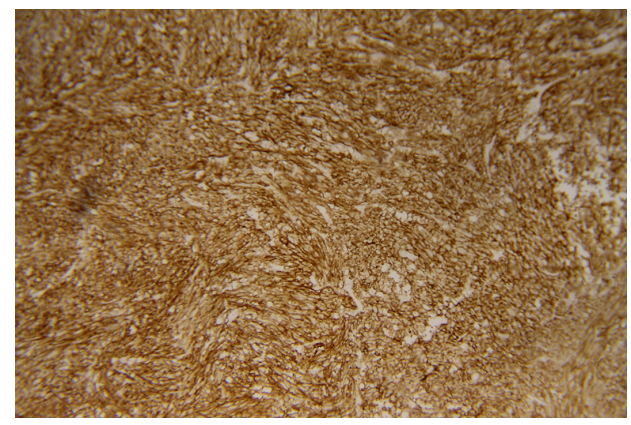

Fig.6: Immunohistochemistry showing neoplastic cells positive for DOG1.

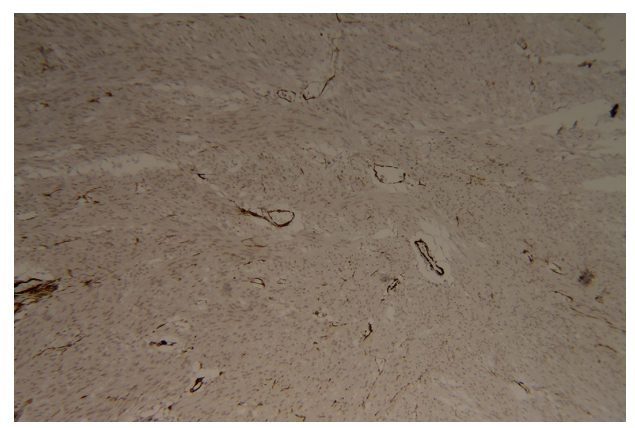

Fig.7: Immunohistochemistry showing neoplastic cells negative for smooth muscle actin. 
dose can be increased to $800 \mathrm{mg} /$ day. Duration of treatment is one year. For advanced disease duration of treatment is three years [24]. Our patient is on imatinib $400 \mathrm{mg} /$ day for last six months. Hence neurofibromatosis type 1 associated NF-1 mutation affects RAS-MAP kinase pathway. C-KIT mutation also affects RAS-MAP kinase and PI3K-AKT pathway. The downstream path for both diseases are same, ultimately patient develops GIST which shows association between neurofibromatosis type 1 and GIST. Further molecular studies are needed to identify the exact reason for overlap.

\section{Conclusion}

Neurofibromatosis and GIST are two different diseases but they can also be associated. Always look for extra-cutaneous manifestations in neurofibromatosis patients. Investigate thoroughly so that you don't miss any lesion which can be missed during clinical examination.

Contributors: AS: manuscript writing, literature review, and histopathology; NP, PC: critical inputs into the manuscript and surgery; DG: literature review, discussion and histopathology. AS will act as a study guarantor. All authors approved the final version of this manuscript and are responsible for all aspects of the study.

Funding: None; Competing interests: None stated.

\section{References}

1. Ferner, RE. Neurofibromatosis 1 and neurofibromatosis 2: A twenty first century perspective. Lancet Neurol. 2007;6:340-351.

2. Brems H, BeertE, de RavelT, Legius E. Mechanisms in the pathogenesis of malignant tumors in neurofibromatosis type 1. Lancet Oncol. 2009;10:508-515.

3. Takazawa Y, Sakurai S, Sakuma Y, Ikeda T, Yamaguchi $\mathrm{J}$, Hashizume $\mathrm{Y}$, et al. Gastrointestinal stromal tumors in patients with neurofibromatosis type 1 (Von Reckinghausen's disease). Am J Surg Pathol. 2005;29:755-763.

4. Corless CL, Fletcher JA, Heinrich MC. Biology of gastrointestinal stromal tumors. Journal of Clinical Oncology. 2004;22:3813-3825.

5. Heinrich MC, Corless CL, Demetri GD, Blanke CD, Mehren VM, Joensuu $\mathrm{H}$, et al. Kinase mutations and Imatinib response in patients with metastatic gastrointestinal stromal tumors. Journal of Clinical
Oncology. 2003;21:4342-4349.

6. Ferner RE, Huson SM, Thomas N, Moss G, Willshaw $\mathrm{H}$, Evans DG, et al. Guidelines for the diagnosis and management of individuals with neurofibromatosis. J Med Genet. 2007;44:81-88.

7. Boyd KP, Korf BR, Theas A. Neurofibromatosis type 1 . J Am Acad Dermatol. 2009;61:1-16.

8. Sehgal VN, Verma P, Chatterjee K. Type 1 Neurofibromatosis (von Recklinghausen Disease). Cutis. 2015;96:E23-E26.

9. Cheng SP, Huang MJ, Yang TL, Tzen CY, Liu CL, Liu TP, et al. Neurofibromatosis with gastrointestinal stromal tumors. Insight into the association. Dig Dis Sci. 2004;49:1165-1169.

10. Zoller ME, Rembeck B, Oden A, Samuelsson M, Angervall $\mathrm{L}$, et al. Malignant and benign tumors in patients with neurofibromatosis type 1 in a defined Swedish population. Cancer. 1997;79:2125-2131.

11. Kindblom LG, Remotti HE, Aldenborg F, MeisKindblom JM. Gastrointestinal pacemaker cell tumor (GIPACT): Gastrointestinal stromal tumors show phenotypic characteristics of the interstitial cells of Cajal. Am J Pathol. 1998;152:1259-1269.

12. Robinson TL, Sircar K, Hewlett BR, Chorneyko K, Riddell RH, Huizinga JD. Gastrointestinal stromal tumors may originate from a subset of $\mathrm{CD} 34$ positive interstitial cells of Cajal. Am J Pathol. 2000;156:11571163.

13. Torlhashi S, Nishi K, Tokutomi Y, Nishi T, Ward S, Sanders KM. Blockade of KIT signaling induces transdifferentiation of interstitial cells of Cajal to a smooth muscle phenotype. Gastroenterology. 1999;117:140148.

14. Heinrich MC, Rubin BP, Longley BJ, Fletcher JA. Biology and genetic aspects of gastrointestinal stromal tumors: KIT activation and cytogenetic alterations. Hum Pathol. 2002;33:484-495.

15. Corless CL, McGreevey L, Haley A, Town A, Heinrich MC. KIT mutations are common in incidental gastrointestinal stromal tumors one centimeter or less in size. Am J Pathol. 2002;160:1567-1572.

16. Prakash S, Sarran L, Socci N, Dematteo RP, Eisenstat $\mathrm{J}$, Greco AM, et al. Gastrointestinal stromal tumors in children and young adults: a clinicopathologic, molecular and genomic study of 15 cases and review of the literature. J Pediatr Hematol Oncol. 2005;27:179187.

17. Lasota J, Wozniak A, Sarlomo-Rikala M, Rys J, Kordek $\mathrm{R}$, Nassar A, et al. Mutations in exon 9 and 13 of KIT gene are rare events in gastrointestinal stromal tumors. A study of 200 cases. Am J Pathol. 2000;157:1091-95.

18. Penzel R, Aulmann S, Mock M, Schwarzbach M, Riecker RJ, Mechtershejmer G. The location of KIT 
and PDGFRA gene mutations in gastrointestinal stromal tumors is site and phenotype associated. J Clin Pathol. 2005;58:634-639.

19. Heinrich MC, Corless CL, Duensing A, McGreevey $\mathrm{L}$, Chen CJ, Joseph $\mathrm{N}$, et al. PDGFRA activating mutations in gastrointestinal stromal tumors. Science. 2003;299:708-710.

20. Nemoto H, Tate G, Schirinzi A, Suzuki T, Sasaya $\mathrm{S}$, Yoshizawa Y, et al. Novel NF1 gene mutation in a Japanese patient with neurofibromatosis type 1 and a gastrointestinal stromal tumor. J Gastroenterol. 2006;41:378-382.

21. Kumar V, Abbas A, Aster J. Robbins \& Cotran Pathologic Basis of Disease. $9^{\text {th }}$ ed. Elsevier. 2017; Vol 1:285-86.
22. Linnekin D. Early signaling pathways activated by c-KIT in hematopietic cells. Int J Biochem Cell Biol. 1999;31:1053-1074.

23. Ning ZQ, Li J, Arceci RJ. Signal transducer and activator of transcription 3 activation is required for $\operatorname{Asp}(816)$ mutant c-KIT- mediated cytokine- independent survival and proliferation in human leukemia cells. Blood. 2001;97:3559-3567.

24. Reichardt P, Blay JY, Boukovinas I, Brodowicz T, Broto JM, Casali PG, et al. Adjuvant therapy in primary GIST: State of the art. Annals of Oncology. 2012;23:27762781 . 